\title{
Are Newborns of Immigrant Mothers More at Risk of Poorer Perinatal Health Than Those of Natives- born Mothers? One Size Does Not Fit All. A Population-based Study, Montreal, Quebec.
}

\author{
Myriam De Spiegelaere \\ Universite Libre de Bruxelles \\ Marie-Pierre Sylvestre \\ Universite de Montreal \\ Marie-France Raynault \\ Universite de Montreal
}

Mouctar Sow ( $\nabla$ sowmouctar@yahoo.fr)

Universite de Montreal https://orcid.org/0000-0001-8038-6326

Research

Keywords: Health inequalities, Perinatal health, Immigrants, Adverse birth outcomes, Poverty, Socioeconomic status, Low birth weight, preterm, Immigration

Posted Date: March 2nd, 2021

DOI: https://doi.org/10.21203/rs.3.rs-256614/v1

License: (c) (1) This work is licensed under a Creative Commons Attribution 4.0 International License.

Read Full License 


\title{
Are newborns of immigrant mothers more at risk of poorer perinatal health than those of natives-born mothers? One size does not fit all.
}

\section{A population-based study, Montreal, Quebec.}

Mouctar Sow ${ }^{* 1,2,3}$, Myriam De Spiegelaere ${ }^{2}$, Marie-Pierre Sylvestre ${ }^{1,4}$, and Marie-France Raynault ${ }^{1,3}$

\begin{abstract}
Background The risk of unfavourable pregnancy outcomes for immigrant mothers varies according to their birthplace, socioeconomic status (SES) and comparison group. This study aims to identify the characteristics of Montreal newborns who are more or less at risk of LBW, prematurity and SGA, according to the mother's birthplace and SES.
\end{abstract}

Methods The analysis focuses on all singleton live births in Montreal between 2003 and 2012 $(\mathrm{N}=214,620)$. Logistic regression models were estimated using generalized estimating equations in order to: 1) compare the risk of adverse pregnancy outcomes between Canadianborn and immigrant mothers. The latter were categorised into 8 groups according to world regions; 2 ) estimate the odds ratio of the association between adverse pregnancy outcomes and the mother's SES (education and income quintile) for each group.

Results The risk of LBW, prematurity and SGA vary considerably depending on the mother's birthplace. For these three outcomes, mothers from the Caribbean and South Asia have a higher prevalence than all other groups. Three other groups compare favourably to Canadianborn mothers: mothers from North Africa, Europe \& the USA, and Central and West Asia.

The association between SES and unfavourable pregnancy outcomes varies from one group of mothers to another. Among Canadian-born mothers, there is a classic health gradient, with low SES mothers being particularly vulnerable. While income is not associated with the risk of adverse outcomes among immigrant mothers, education is for many groups. The association is however weaker than for Canadian-born mothers.

Conclusions It is important to assess the influence of both immigration and SES to better identify the children who are most at risk of experiencing perinatal health concerns. In Montreal, some immigrant women are particularly vulnerable, but so are socioeconomically disadvantaged native Canadian women. Conversely, North African-born mothers with low SES present a particularly low risk. It has also been found that a high level of education reduces the risk among several groups of immigrant women, as opposed to findings in other contexts.

Keywords: Health inequalities, Perinatal health, Immigrants, Adverse birth outcomes, Poverty, Socioeconomic status, Low birth weight, preterm, Immigration.

\footnotetext{
*Correspondence: mamasow@ulb.ac.be ; mamadou.mouctar.sow@umontreal.ca ; sowmouctar@yahoo.fr

${ }^{1}$ Department of Social and Preventive Medicine, School of Public Health, Université de Montréal, Montreal, QC, Canada

¿Université Libre de Bruxelles, École de santé publique, Brussels, Belgium

${ }^{3}$ Lea-Roback Research Centre on Social Inequalities in Health, CRCHUM, Quebec, Canada

${ }^{4}$ Centre de recherche du centre hospitalier de l'Université de Montréal (CRCHUM), Montreal, QC, Canada
}

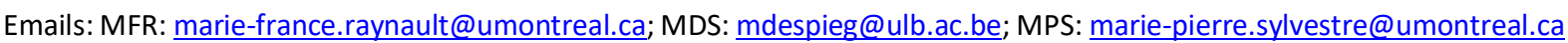




\section{BACKROUND}

Reducing perinatal health inequalities is a major public health priority. Children who are born prematurely or with a low birth weight are at a higher risk of perinatal mortality, developmental disorders and health problems during childhood and adulthood (1-3). The influence of SES and migration on the health of newborns varies according to the origin of the mothers, the comparison group, and health and socioeconomic status indicators (4-10) (410).

We have carried out several studies in the Belgian context in order to investigate the joint influence of SES and migration on the health of newborn babies $(8,9,11,12)$. Several results emerge from these studies. First, the risk of adverse pregnancy outcomes varies according to the mother's birthplace. North African-born mothers in particular are found to be at a lower risk of experiencing adverse pregnancy outcomes compared to Belgian-born mothers, while mothers from sub-Saharan Africa are at a higher risk. Second, these results differ significantly according to SES. Among mothers with low SES, these two immigrant groups are at a significantly lower risk of LBW than native-born mothers. On the other hand, among mothers with a higher SES, those born in Belgium are at a lower risk of LBW than mothers from subSaharan Africa, and the additional risk compared to mothers from North Africa decreases significantly. In other words, Belgian-born mothers with low SES are particularly vulnerable, while the opposite can be observed among high SES mothers. Third, the association between SES and perinatal health varies according to the mother's birthplace. Mothers born in Belgium show a classic health gradient, while the risk of LBW does not differ according to the mother's level of education among non-European immigrant women.

This study aims to apply this analysis to other contexts. The Montreal context offers a good point of comparison. Immigrant households are strongly represented in Montreal, just like in Brussels. More than half of all births come from immigrant households. However, social and migration policies differ between the two regions. Our analysis focuses on births to mothers residing in Montreal - the largest metropolis in the province of Quebec and the secondlargest city in all of Canada. It aims to assess the influence of SES and migration status on perinatal health by answering two questions: a) does the risk of adverse pregnancy outcomes vary according to the mother's birthplace; and b) does the association between SES and adverse pregnancy outcomes differ according to the mother's birthplace? 
This analysis is all the more relevant given the scarcity of research on the influence of SES on pregnancy outcomes among immigrant women in Quebec. The existing studies on this subject, however, do not usually distinguish between different immigrant groups when interpreting the results $(13,14)$. Such a distinction could highlight important differences, and thus help us better identify the newborns most at risk of experiencing perinatal health concerns. This study is, to our knowledge, the first in Quebec to adopt such an approach.

\section{METHODS}

\section{Population and data sources}

This population-based study focuses on singleton live births to mothers residing in the Montreal area between 2003 and 2012. Births which occurred before 22 weeks of gestation were excluded from our analyses. The data come from birth records. The analytical sample includes 214,620 births.

\section{Variables}

The analysis focuses on three perinatal indicators: low birth weight (LBW), i.e. birth weight below 2500 grams; preterm birth, which refers to a birth before 37 weeks of gestation; and low weight for gestational age (SGA), which refers to a birth weight below the 10th percentile of its age group. The most recent curve available in Canada was used as the reference for the SGA estimate (15). These three adverse pregnancy outcomes were analysed according to the mother's country of birth and SES.

The mother's country of birth was used to distinguish between women born in Canada and immigrants. The latter were divided into 8 categories according to different regions of the world. The two SES variables considered are the mother's level of education and the neighbourhood income.

The level of education was divided into three categories based on the number of years of education completed: mothers with secondary $V$ degree (high school), mothers with a college education level, and mothers who have reached university-level education. 
Neighbourhood income refers to the average income of the dissemination area where the mother resides. The dissemination area is the most common geographic unit for which census data is made available (16). This information is incorporated into birth records with postal codes. The average income of the neighbourhood was categorised into quintiles.

\section{Statistical analyses}

First, logistic regression models were estimated using generalized estimating in order to compare the risk of adverse pregnancy outcomes between Canadian-born mothers and 8 groups of immigrant mothers.

Second, stratified analysed was performed to estimate the odds ratio of the association between adverse pregnancy outcomes and the mother's SES (education and income quintile) for each group of mothers. For this second point, we present the results concerning LBW. The results concerning preterm birth and SGA, which are consistent with those found on LBW, are provided in the appendix (supplemental files $1 \& 2$ ). The mother's marital status, age and parity as well as the sex of the child were used as adjustment variables. For SGA, the adjustment does not take the sex of the child into account, since the reference curve estimating SGA already factors it in.

\section{RESULTS}

\section{Socio-demographic profile of mothers and newborns (Table 1).}

Among 21,4620 singleton live births over the period studied (2002-2012), more than half of these babies are born to an immigrant mother. Among these foreign-born mothers, North African women are the most represented, followed by mothers from Europe or the United States. These two groups account for about one third of immigrant mothers, and one fifth of all births.

The socioeconomic status of Montreal mothers varies according to the mother's origin. Generally speaking, three profiles can be distinguished according to the mother's education level and the average income of the area where she lives: a) The most favoured groups: mothers born in Canada, Central or West Asia, and Europe or the United States. These mothers have a proportionally high likelihood of living in more affluent areas (around 26\%) 
and also of having a university degree (52\%, $70 \%$ and $55 \%$, respectively); b) The particularly disadvantaged groups: mothers from the Caribbean and South Asia. These women are much more likely to have an unfinished high school education ( $48 \%$ and $44 \%$ respectively), and to live in underprivileged neighbourhoods, especially for mothers from South Asia (41\%); c) The "intermediate" groups: mothers from North Africa, Sub-Saharan Africa, Latin America, and East and Southeast Asia. The proportion of highly educated mothers is relatively high among these women, especially among North African-born mothers (62\%). However, many of them live in underprivileged areas. In both groups of African mothers, less than $10 \%$ of the women live in affluent neighbourhoods; the same applies to mothers of Caribbean origin.

About $10 \%$ of Canadian-born mothers are single parents, whereas $5 \%$ of mothers from North Africa, Europe or the United States, and Asia are single. The highest proportions of single mothers are found among Caribbean (29\%), sub-Saharan (20\%) and Latin American women (16\%) 
Table1. Characteristics of mothers and newborns, according to the mother's birthplace (2003-2012)

\begin{tabular}{|c|c|c|c|c|c|c|c|c|c|c|}
\hline $\mathrm{N}$ & $\begin{array}{l}\text { All births } \\
214620^{*}\end{array}$ & $\begin{array}{l}\text { Canada } \\
97520\end{array}$ & \begin{tabular}{|l|} 
North \\
Africa \\
24312 \\
\end{tabular} & $\begin{array}{l}\text { SS Africa } \\
7951\end{array}$ & \begin{tabular}{|l} 
Caribbean \\
10494
\end{tabular} & \begin{tabular}{|l|} 
Latin \\
America \\
10022 \\
\end{tabular} & $\begin{array}{l}\text { South } \\
\text { Asia } \\
7960\end{array}$ & \begin{tabular}{|l|} 
Central \& \\
West Asia \\
9236
\end{tabular} & $\begin{array}{l}\text { East Asia } \\
\text { \& South-E } \\
13372\end{array}$ & $\begin{array}{l}\text { Europe } \\
\& \text { USA } \\
16114\end{array}$ \\
\hline$\%$ of births & 100 & 45.4 & 11.3 & 3.7 & 4.9 & 4.7 & 3.7 & 4.3 & 6.2 & 7.5 \\
\hline Maternal education (n) & 200943 & 92943 & 22954 & 7496 & 9853 & 9532 & 7429 & 8747 & 12344 & 15373 \\
\hline University (\%) & 50.58 & 51.79 & 61.57 & 42.53 & 22.97 & 41.37 & 25.24 & 54.09 & 48.10 & 70.29 \\
\hline College (\%) & 24.71 & 24.81 & 21.44 & 28.18 & 29.18 & 23.77 & 31.16 & 23.12 & 30.80 & 18.37 \\
\hline High school (\%) & 24.70 & 23.41 & 16.99 & 29.30 & 47.85 & 34.86 & 43.60 & 22.80 & 21.10 & 11.34 \\
\hline Income Quintile (n) & 211265 & 95642 & 24155 & 7874 & 10428 & 9916 & 7868 & 9036 & 13124 & 15867 \\
\hline Top (\%) & 20.00 & 26.57 & 9.06 & 8.61 & 8.31 & 13.55 & 11.55 & 25.79 & 15.16 & 26.80 \\
\hline Fourth (\%) & 20.00 & 23.34 & 16.90 & 15.56 & 15.45 & 18.99 & 12.79 & 17.75 & 16.17 & 22.53 \\
\hline Middle (\%) & 20.00 & 20.35 & 21.84 & 19.81 & 21.69 & 21.18 & 15.10 & 18.89 & 18.84 & 18.38 \\
\hline Second (\%) & 20.00 & 17.75 & 25.22 & 22.06 & 26.27 & 23.32 & 19.61 & 18.28 & 21.25 & 17.20 \\
\hline Bottom (\%) & 20.00 & 12.00 & 26.98 & 33.96 & 28.28 & 22.96 & 40.95 & 19.29 & 28.57 & 15.09 \\
\hline Marital status (n) & 208249 & 95139 & 23599 & 7740 & 10225 & 9786 & 7681 & 8888 & 12904 & 15616 \\
\hline Single (\%) & 9.94 & 10.18 & 4.25 & 20.36 & 29.49 & 15.71 & 4.23 & 3.09 & 6.90 & 4.44 \\
\hline Parity (n) & 214620 & 97520 & 24312 & 7951 & 10494 & 10022 & 7960 & 9236 & 13372 & 16114 \\
\hline $0(\%)$ & 48.65 & 53.83 & 42.69 & 39.71 & 38.79 & 46.16 & 40.08 & 39.38 & 50.32 & 50.44 \\
\hline 1-2 (\%) & 45.36 & 41.44 & 51.74 & 48.92 & 50.00 & 47.14 & 51.97 & 49.23 & 46.79 & 43.57 \\
\hline 3 (\%) & 5.99 & 4.73 & 5.57 & 11.37 & 11.21 & 6.71 & 7.95 & 11.39 & 2.89 & 5.99 \\
\hline Maternal age (n) & 214620 & 97520 & 24312 & 7951 & 10494 & 10022 & 7960 & 9236 & 13372 & 16114 \\
\hline$<20(\%)$ & 2.17 & 3.30 & 0.44 & 1.45 & 2.44 & 2.66 & 0.79 & 1.19 & 0.37 & 0.81 \\
\hline $20-29$ (\%) & 39.73 & 42.05 & 35.40 & 43.87 & 37.35 & 41.61 & 52.99 & 43.17 & 26.20 & 31.43 \\
\hline 30-39 (\%) & 51.48 & 49.37 & 54.96 & 48.11 & 50.10 & 49.45 & 42.01 & 49.04 & 63.59 & 60.08 \\
\hline$\geq 40(\%)$ & 6.62 & 5.27 & 9.20 & 6.58 & 10.11 & 6.28 & 4.21 & 6.60 & 9.84 & 7.68 \\
\hline Infant sex (n) & 214620 & 97520 & 24312 & 7951 & 10494 & 10022 & 7960 & 9236 & 13372 & 16114 \\
\hline Female & 48.62 & 48.42 & 48.92 & 48.62 & 49.49 & 48.52 & 48.54 & 47.62 & 48.16 & 48.98 \\
\hline
\end{tabular}

*Including the rest of the world ( $n=13007)$ and unknown $(n=4632)$

\section{Risk of adverse pregnancy outcomes according to the mother's birthplace (Table 2).}

The risks of low birth weight, prematurity and SGA vary considerably depending on the mother's birthplace. A first group of women from sub-Saharan Africa, the Caribbean and South Asia present a significantly higher risk than Canadian-born mothers for the three perinatal indicators analysed; the excess risk is particularly high for children whose mothers are from the Caribbean and South Asia. A second group of mothers from North Africa, Europe and the United States, and Central and West Asia, present lower risks than Canadian-born mothers, except for the risk of SGA in Central and West Asian mothers which is similar to that of Canadian-born mothers. The prevalence in the third and final group, which is made up of 
Latin American as well as East and Southeast Asian mothers, are similar to that of Canadianborn mothers, except for the higher prevalence of SGA in Asian mothers.

These trends do not change after adjusting for the mother's and newborn's characteristics (education, income, marital status, parity and sex of the child), with three exceptions: the excess risk of prematurity of mothers from sub-Saharan Africa disappears; the risk of SGA in mothers from Europe or the United States becomes similar to that of Canadian-born mothers, and the risk of SGA of mothers born in Central and West Asia slightly increases.

Table 2. ORs $(95 \% \mathrm{Cl})$ of the association between adverse birth outcomes and maternal birthplace

\begin{tabular}{|c|c|c|c|c|c|c|}
\hline \multirow[b]{3}{*}{ Maternal birth place } & \multicolumn{6}{|c|}{ UNADJUSTED ORs (Cl 95\%) } \\
\hline & \multirow[t]{2}{*}{$\%$} & \multirow[t]{2}{*}{ LBW } & \multirow[t]{2}{*}{$\%$} & \multirow[t]{2}{*}{ PRETERM } & \multirow[t]{2}{*}{$\%$} & \multirow[t]{2}{*}{ SGA } \\
\hline & & & & & & \\
\hline Canada & 4.32 & 1 & 5.72 & 1 & 8.67 & 1 \\
\hline Caribbean & 8.22 & $1.96(1.81-2.11)^{\mathrm{a}}$ & 9.66 & $1.75(1.63-1.87)^{a}$ & 11.54 & $1.37(1.28-1.46)^{\mathrm{a}}$ \\
\hline South Asia & 7.66 & $1.80(1.64-1.97)^{a}$ & 7.94 & $1.41(1.29-1.54)^{a}$ & 15.83 & $1.96(1.83-2.09)^{\mathrm{a}}$ \\
\hline Sub-saharan Africa & 5.41 & $1.25(1.13-1.39)^{a}$ & 6.44 & $1.13(1.02-1.24)^{c}$ & 9.47 & $1.09(1.01-1.18)^{\mathrm{c}}$ \\
\hline North Africa & 3.01 & $0.68(0.63-0.74)^{a}$ & 4.17 & $0.71(0.67-0.77)^{a}$ & 7.06 & $0.80(0.76-0.84)^{a}$ \\
\hline Europe \& USA & 3.20 & $0.73(0.67-0.80)^{a}$ & 4.72 & $0.82(0.76-0.88)^{a}$ & 8.09 & $0.93(0.87-0.98)^{c}$ \\
\hline Latin America & 4.23 & $0.97(0.87-1.07)$ & 6.13 & 1.07 (0.98-1.17) & 8.69 & 0.99 (0.93-1.07) \\
\hline Central \& West Asia & 3.27 & $0.74(0.66-0.84)^{a}$ & 4.42 & $0.76(0.69-0.85)^{\mathrm{a}}$ & 8.78 & $1.01(0.93-1.08)$ \\
\hline \multirow[t]{3}{*}{ East \& Southeast Asia } & 4.66 & $1.06(0.97-1.16)$ & 6.03 & $1.05(0.97-1.13)$ & 10.99 & $1.29(1.21-1.37)^{\mathrm{a}}$ \\
\hline & \multicolumn{6}{|c|}{ ADJUSTED ORs (Cl 95\%) } \\
\hline & & LBW & & PRETERM & & SGA \\
\hline \multicolumn{7}{|l|}{ Maternal birth place } \\
\hline Canada & & 1 & & 1 & & 1 \\
\hline Caribbean & & $1.75(1.61-1.91)^{\mathrm{a}}$ & & $1.53(1.41-1.65)^{\mathrm{a}}$ & & $1.36(1.27-1.46)^{\mathrm{a}}$ \\
\hline South Asia & & $1.79(1.63-1.98)^{\mathrm{a}}$ & & $1.36(1.24-1.49)^{a}$ & & $2.03(1.89-2.18)^{a}$ \\
\hline Sub-saharan Africa & & $1.22(1.09-1.36)^{a}$ & & $1.08(0.98-1.20)$ & & $1.14(1.05-1.24)^{b}$ \\
\hline North Africa & & $0.73(0.67-0.79)^{a}$ & & $0.75(0.69-0.80)^{a}$ & & $0.87(0.82-0.92)^{a}$ \\
\hline Europe \& USA & & $0.79(0.72-0.87)^{a}$ & & $0.87(0.80-0.94)^{a}$ & & $0.99(0.93-1.05)$ \\
\hline Latin America & & $0.94(0.84-1.04)$ & & $1.04(0.95-1.14)$ & & $1.01(0.93-1.09)$ \\
\hline Central \& West Asia & & $0.81(0.71-0.92)^{a}$ & & $0.79(0.70-0.88)^{a}$ & & $1.13(1.04-1.22)^{b}$ \\
\hline East \& Southeast Asia & & $1.04(0.941 .14)$ & & $1.03(0.95-1.12)$ & & $1.30(1.22-1.39)^{\mathrm{a}}$ \\
\hline
\end{tabular}




\section{Predictors of SIH according to mother's birthplace (Tables $3 \& 4$ ).}

The influence of socioeconomic factors on the risk of LBW differs according to the mother's birthplace. We observe a classic social gradient among Canadian-born mothers: income and education level are inversely associated with LBW. The differences according to SES are relatively large.

Among immigrant mothers, the association between SES and LBW varies according to the immigrant group and SES indicator. In no group is neighbourhood income associated with the risk of LBW. The mother's education level, on the other hand, influences the risk of LBW for several immigrant groups. A very low level of education increases this risk (before and after adjustment) for all immigrant women except for mothers from North Africa, the Caribbean and South Asia. Among immigrant women, the impact of the education level is more pronounced for women from Europe or the USA and from Central or West Asia. However, unlike Canadian-born mothers, there is no health gradient among immigrant women. 
Table 3. Associations between low birth weight and SES according to mother's birthplace

\begin{tabular}{|c|c|c|c|c|c|c|c|c|c|c|}
\hline & \multicolumn{10}{|c|}{ CRUDE ORs (Cl 95\%) } \\
\hline & \multicolumn{2}{|r|}{ Canada } & \multicolumn{2}{|r|}{ Caribbean } & \multicolumn{2}{|c|}{ South Asia } & \multicolumn{2}{|r|}{ SS Africa } & \multicolumn{2}{|r|}{ North Africa } \\
\hline & $\%$ & OR $(95 \% \mathrm{Cl})$ & $\%$ & OR $(95 \% \mathrm{Cl})$ & $\%$ & OR $(95 \% \mathrm{Cl})$ & $\%$ & OR $(95 \% \mathrm{Cl})$ & $\%$ & OR $(95 \% \mathrm{Cl})$ \\
\hline Maternal education & & & & & & & & & & \\
\hline Univerty & 3.43 & 1 & 8.22 & 1 & 7.47 & 1 & 5.02 & 1 & 3.06 & 1 \\
\hline College & 4.26 & $1.25(1.15-1.35)^{a}$ & 7.48 & $0.90(0.73-1.10)$ & 8.38 & $1.13(1.07-1.16)$ & 5.63 & $1.13(0.89-1.44)$ & 2.91 & $0.94(0.78-1.14)$ \\
\hline High school & 6.20 & $1.84(1.71-2.00)^{a}$ & 8.70 & $1.06(0.88-1.27)$ & 7.07 & $0.94(0.75-1.17)$ & 5.65 & $1.13(0.89-1.44)$ & 2.90 & $0.94(0.76-1.16)$ \\
\hline Income Quintile & & & & & & & & & & \\
\hline Top & 3.31 & 1 & 9.23 & 1 & 6.60 & 1 & 6.05 & 1 & 3.34 & 1 \\
\hline Fourth & 4.01 & $1.22(1.10-1.35)^{a}$ & 8.51 & $0.91(0.68-1.22)$ & 7.75 & $1.18(0.83-1.68)$ & 6.12 & $1.01(0.68-1.50)$ & 2.79 & $0.83(0.61-1.12)$ \\
\hline Midlle & 4.62 & $1.42(1.28-1.57)^{\mathrm{a}}$ & 8.13 & $0.87(0.66-1.14)$ & 8.42 & $1.31(0.94-1.82)$ & 5.26 & $0.87(0.58-1.28)$ & 2.82 & $0.84(0.63-1.12)$ \\
\hline Second & 4.93 & $1.52(1.37-1.68)^{a}$ & 7.92 & $0.84(0.64-1.11)$ & 7.00 & $1.06(0.77-1.47)$ & 4.72 & $0.77(0.52-1.14)$ & 2.99 & $0.90(0.68-1.18)$ \\
\hline Bottom & 5.82 & $1.80(1.61-2.00)^{a}$ & 8.14 & $0.87(0.66-1.33)$ & 7.98 & $1.22(0.91-1.63$ & 5.50 & $0.93(0.65-1.33)$ & 3.18 & $0.95(0.72-1.25)$ \\
\hline
\end{tabular}

\begin{tabular}{|c|c|c|c|c|c|}
\hline \multirow[b]{2}{*}{ Maternal education } & \multicolumn{5}{|c|}{ AJUSTED ORs (Cl 95\%) } \\
\hline & Canada & Caribbean & South Asia & SS Africa & North Africa \\
\hline Univerty & 1 & 1 & 1 & 1 & 1 \\
\hline College & $1.25(1.15-1.36)^{a}$ & $0.95(0.77-1.18)$ & $1.24(0.98-1.58)$ & $1.27(0.98-1.64)$ & $0.99(0.81-1.21)$ \\
\hline High school & $1.77(1.62-1.94)^{\mathrm{a}}$ & $1.19(0.98-1.45)$ & $1.05(0.84-1.33)$ & $1.40(1.08-1.80)^{c}$ & $1.05(0.84-1.30)$ \\
\hline \multicolumn{6}{|l|}{ Income Quintile } \\
\hline Top & 1 & 1 & 1 & 1 & 1 \\
\hline Fourth & $1.09(0.98-1.21)$ & $0.85(0.62-1.14)$ & $1.19(0.82-1.71)$ & $1.04(0.69-1.57)$ & $0.82(0.59-1.11)$ \\
\hline Midlle & $1.21(1.09-1.35)^{\mathrm{a}}$ & $0.85(0.64-1.12)$ & $1.32(0.93-1.88)$ & $0.87(0.58-1.31)$ & $0.85(0.62-1.14)$ \\
\hline Second & $1.24(1.11-1.38)^{\mathrm{a}}$ & $0.79(0.60-1.05)$ & $1.02(0.72-1.44)$ & $0.76(0.50-1.14)$ & $0.86(0.65-1.15)$ \\
\hline Bottom & $1.37(1.21-1.54)^{\mathrm{a}}$ & $0.85(0.64-1.12)$ & $1.21(0.89-1.66)$ & $0.91(0.63-1.34)$ & $0.92(0.69-1.23)$ \\
\hline
\end{tabular}


Table 4. Associations between low birth weight and SES according to mother's birthplace

\begin{tabular}{|c|c|c|c|c|c|c|c|c|c|c|}
\hline & \multicolumn{10}{|c|}{ CRUDE ORs (Cl 95\%) } \\
\hline & \multicolumn{2}{|r|}{ Canada } & \multicolumn{2}{|r|}{ Europe \& USA } & \multicolumn{2}{|c|}{ Latin America } & \multicolumn{2}{|r|}{ Central/West Asia } & \multicolumn{2}{|c|}{ East/Southeast Asia } \\
\hline & $\%$ & OR $(95 \% \mathrm{Cl})$ & $\%$ & OR $(95 \% \mathrm{Cl})$ & $\%$ & OR $(95 \% \mathrm{Cl})$ & $\%$ & OR $(95 \% \mathrm{Cl})$ & $\%$ & OR $(95 \% \mathrm{Cl})$ \\
\hline Maternal education & & & & & & & & & & \\
\hline Univerty & 3.43 & 1 & 3.11 & 1 & 4.01 & 1 & 2.87 & 1 & 4.11 & 1 \\
\hline College & 4.26 & $1.25(1.15-1.35)^{\mathrm{a}}$ & 2.62 & $0.84(0.65-1.08)$ & 3.89 & $0.96(0.73-1.25)$ & 3.02 & $1.05(0.77-1.43)$ & 5.37 & $1.32(1.09-1.60)^{b}$ \\
\hline High school & 6.20 & $1.84(1.71-2.00)^{\mathrm{a}}$ & 4.59 & $1.50(1.17-1.92)^{\mathrm{a}}$ & 4.63 & $1.15(0.92-1.45)$ & 4.11 & $1.45(1.09-1.92)^{\mathrm{b}}$ & 4.91 & $1.20(0.96-1.50)$ \\
\hline Income Quintile & & & & & & & & & & \\
\hline Top & 3.31 & 1 & 3.15 & 1 & 3.57 & 1 & 3.18 & 1 & 4.42 & 1 \\
\hline Fourth & 4.01 & $1.22(1.10-1.35)^{\mathrm{a}}$ & 2.94 & $0.93(0.71-1.20)$ & 4.46 & $1.26(0.88-1.82)$ & 3.55 & $1.11(0.77-1.59)$ & 4.81 & $1.09(0.81-1.46)$ \\
\hline Midlle & 4.62 & $1.42(1.28-1.57)^{a}$ & 3.33 & $1.05(0.81-1.38)$ & 4.48 & $1.26(0.88-1.80)$ & 2.99 & $0.95(0.66-1.37)$ & 4.25 & $0.95(0.71-1.28)$ \\
\hline Second & 4.93 & $1.52(1.37-1.68)^{a}$ & 2.92 & $0.92(0.69-1.23)$ & 4.54 & $1.28(0.90-1.82)$ & 3.09 & $0.98(0.68-1.42)$ & 4.91 & $1.11(0.84-1.46)$ \\
\hline Bottom & 5.82 & $1.80(1.61-2.00)^{\mathrm{a}}$ & 3.90 & $1.25(0.95-1.63)$ & 4.00 & $1.12(0.78-1.61)$ & 3.67 & $1.18(0.83-1.67)$ & 4.85 & $1.10(0.85-1.43)$ \\
\hline
\end{tabular}

\begin{tabular}{|c|c|c|c|c|c|}
\hline & \multicolumn{5}{|c|}{ AJUSTED ORs (Cl 95\%) } \\
\hline & Canada & Europe \& USA & Latin America & Central/West Asia & East/South-E Asia \\
\hline \multicolumn{6}{|l|}{ Maternal education } \\
\hline Univerty & 1 & 1 & 1 & 1 & 1 \\
\hline College & $1.25(1.15-1.36)^{a}$ & $0.88(0.67-1.15)$ & $1.02(0.77-1.35)$ & $1.06(0.76-1.48)$ & $1.30(1.06-1.58)^{b}$ \\
\hline High school & $1.77(1.62-1.94)^{a}$ & $1.70(1.29-2.22)^{\mathrm{a}}$ & $1.31(1.00-1.71)$ & $1.63(1.19-2.22)^{b}$ & $1.22(0.96-1.54)$ \\
\hline \multicolumn{6}{|l|}{ Income Quintile } \\
\hline Top & 1 & 1 & 1 & 1 & 1 \\
\hline Fourth & $1.09(0.98-1.21)$ & $0.91(0.70-1.20)$ & $1.28(0.87-1.88)$ & $1.08(0.74-1.57)$ & $1.09(0.81-1.48)$ \\
\hline Midlle & $1.21(1.09-1.35)^{a}$ & $1.02(0.77-1.35)$ & $1.36(0.93-1.99)$ & $0.92(0.62-1.36)$ & $0.86(0.63-1.17)$ \\
\hline Second & $1.24(1.11-1.38)^{a}$ & $0.84(0.62-1.13)$ & $1.33(0.91-1.94)$ & $0.83(0.55-1.24)$ & $1.06(0.79-1.41)$ \\
\hline Bottom & $1.37(1.21-1.54)^{a}$ & $1.17(0.88-1.57)$ & $1.11(0.75-1.63)$ & $1.06(0.72-1.54)$ & $1.08(0.82-1.42)$ \\
\hline
\end{tabular}

${ }^{c} \leq 0.05 ;{ }^{b} \leq 0.01 ;{ }^{a} \leq 0.001$ 


\section{DISCUSSION}

The situation of immigrant mothers in Montreal is far from being homogeneous in socioeconomic terms. There are two extremes: one the one hand, the relatively privileged mothers from Northern Europe and Central and Western Asia, whose profile is comparable to that of Canadian-born mothers, and on the other hand, the more disadvantaged mothers from the Caribbean and South Asia.

Our results show that perinatal health inequities in Montreal are influenced by both the mother's birthplace and socioeconomic status. The discussion addresses three aspects: the marked vulnerability of Caribbean and South Asian mothers, the particularly favourable situation of North African mothers with low SES, and the association between education level and LBW.

\section{Marked vulnerability of Caribbean and South Asian mothers, even among the highly educated}

Other studies found similar results for these two groups. The comparison with these studies, however, has limitations, in particular due to differences in categorisation. For example, in several studies mothers born in the Caribbean were grouped with those born in Latin America $(10,17)$. The same applies for mothers from South Asia, who are often grouped with those from Central Asia (10). Our results show the relevance of analysing the risks of adverse outcomes for these groups separately, at least in the Quebec context.

By distinguishing the prevalence of LBW according to SES among different groups of mothers, our study allows us to better analyse the risk profile of the different groups. Among mothers from the Caribbean and South Asia, there is a very high prevalence of high SES mothers, which is similar to that of low SES mothers. This suggests a relatively high vulnerability of highly educated mothers from these two regions. Comparison with the levels of prevalence observed among Canadian-born women confirms this trend. The differences with the latter are indeed much more marked when comparing the high SES groups. For example, the prevalence of LBW among mothers with less than a high school education is $6.20 \%$ for 
Canadian-born women and $\mathbf{7 . 0 7 \%}$ for South Asian women. For mothers holding a university degree, these figures amount to $3.43 \%$ and $7.47 \%$, respectively.

This could be explained by the fact that these groups of highly educated women are more exposed to risk factors than Canadian-born mothers and other immigrant women of the same SES. For example, we find that these highly educated women are often overqualified for the jobs they do compared to native-born women. While this is also true for other immigrant women, there is also evidence that South Asian women are more likely to work jobs that expose them to precarious working conditions compared to native-born mothers and other groups of immigrant women (18): "... South Asian women are also strongly represented in processing, manufacturing and utilities occupations; over a quarter (26.9\%) of them work these jobs (compared to 9.3\% of all immigrant women)". In addition, South Asian women also have relatively lower average incomes compared to all other groups.

These results suggest that, in the Montreal context, mechanisms of work-related discrimination particularly weaken these women. Authors stress the importance of better studying such mechanisms in order to understand how they contribute to exacerbating health inequalities $(9,19-22)$. Other types of risk factors according to SES could also play a role, namely obesity, tobacco or alcohol consumption, and gestational diabetes. Studies highlighting the distribution of these factors according to SES among different immigrant groups could help explain the differences in risk we observed according to birthplace and SES in different contexts.

Lower vulnerability of North African mothers with low SES in different contexts: a Maghrebi paradox?

North African-born mothers have the lowest levels of prevalence for all three pregnancy outcomes. The difference with Canadian-born mothers can be largely explained by the particularly low levels of prevalence observed among North African mothers of low SES compared to Canadian mothers of low SES, and to all other immigrant women of the same SES. These findings are similar to those in the Brussels context. They are also similar to the situation of Mexican mothers in the United States, which is described as the Mexican paradox $(6,23-25)$. 
The lower vulnerability for this group could be explained by a strengthening of protective factors during pregnancy. In Belgium, it was found that more than half of these women did not work during most of the pregnancy, and were therefore less exposed than other groups, both native and foreign-born, to precarious working conditions during pregnancy. In Quebec, these women are also relatively more likely not to work compared to several other immigrant groups, with an employment rate amounting to less than 45\%. Unlike South Asian and other immigrant women, Arab women are less likely to work strenuous jobs, so those who do work are less exposed to precarious working conditions (18).

Cultural factors, particularly regarding smoking habits, may also be important. In-depth studies are needed to understand the factors that protect these women. Such studies are likely to provide important lessons for perinatal health prevention. It also seems relevant to extend the analysis to other health problems.

\section{Education level: a marker of health inequalities among several immigrant groups}

Differences in risk according to education level are more pronounced for the three most advantaged groups: Canada, Europe \& USA, Central and West Asia. Similar results are found in Brussels, where education is a good predictor of pregnancy outcomes for mothers born in Belgium or in a country of the European Union.

In the Montreal context, we also found that education is associated with LBW in several other immigrant groups, although the association remains weaker than for Canadian-born women. This finding differs from those made in other contexts for some immigrant groups. For example, in Brussels, the risk of LBW does not vary according to education level among mothers from sub-Saharan Africa. Similar findings to those in the Belgian context have been made for some immigrant groups in other contexts (Buttenheim et al., 2010; Goldman et al., 2006; Kimbro et al., 2008)

In a context such as Canada, a country which adopts selective immigration policies on the basis of migrant qualifications, the correlation between education level and labour market opportunities may be stronger than in other contexts. Studies comparing countries with different types of migration policy could help us better understand how the context influences the relationship between education level and pregnancy outcomes among immigrant women. Analyses along these lines prove the relevance of such studies (27). 
In contrast to education level, the risk of LBW does not differ according to income among all immigrant groups. Studies show that the impact of neighbourhood deprivation on health is more pronounced among people who have lived there for a very long time (transgenerational impact of deprivation) (28), which is not the case for recent immigrants. Moreover, among these immigrants, the level of education may be a better indicator of their standard of living in the country of origin than the income of the neighbourhood in the host country. It is important to take their life journey into account in order to better analyse the health impacts of immigration.

\section{Limitations}

The available data does not allow for further exploration of certain hypotheses. Information on working conditions, on length of residence of immigrants or on living habits would have been relevant in this respect. Moreover, the curves generally used to estimate the SGA may not be appropriate for some immigrants (29)

\section{CONCLUSION}

The analysis carried out shows the importance of assessing the influence of both the mother's origin and her socioeconomic status in order to better identify the newborns who are at a greater or lower risk of experiencing perinatal health concerns. In Montreal, it was found that the most vulnerable newborns are those whose mothers come from the Caribbean or South Asia, regardless of the mother's SES, but also children of Canadian-born mothers who are socioeconomically disadvantaged. Conversely, North African mothers with low SES present a particularly low risk. It is also found that a high education level reduces the risk among several immigrant groups, in contrast to findings in other contexts. Future studies should delve deeper into the factors that make certain groups of women more or less vulnerable in different contexts. 


\section{Declarations}

\section{Ethics approval and consent to participate}

Approval was obtained from the Université de Montréal health research ethics board (\# 15004-CERES-D) and the belgian Commission for the Protection of Privacy (\# STAT 04-2014).

Participant consent was not necessary as this study involved the use of a de-identified database.

Consent for publication Not applicable.

\section{Availability of data and materials}

Belgian data are available from the authors upon reasonable request and with permission of Commission for the Protection of Privacy (CPP). Canadian data are available at the Québec Inter-University Center for Social Statistics (QICSS)

Competing interests The authors declare that they have no competing interests.

\section{Funding}

This research was supported by Fonds National de la Recherche Scientifique (FNRS-Belgium) grant number [ $\mathrm{n}^{\circ}$ 22329302], Fonds de la Recherche du Québec-Société et Culture (FRQSC) grant number [197077], and Lea Roback research Centre on social inequalities in health of Montreal. MPS is supported by a Chercheur-Boursier career award from the Fonds de Recherche du Quebec-Santé (FRQS).

\section{Authors' Contributions}

MS performed the design of the study, the statistical analysis and wrote the draft of the manuscript. MDS, MPS and MFR have been involved in revising the manuscript. All authors read and approved the final version of the article.

\section{Acknowledgements}

We would like to thank Statistics Belgium (DGSIE) and the Québec Inter-University Center for Social Statistics (QICSS) for providing the data. 


\section{References}

1. Béatrice N, Lise G, Victoria Z, Louise S. Longitudinal patterns of poverty and health in early childhood: exploring the influence of concurrent, previous, and cumulative poverty on child health outcomes. BMC Pediatr. 2012;12(1):141.

2. Européan Comission. Investing in children: breaking the cycle of disadvantage. 2013. http://ec.europa.eu/justice/fundamental-rights/files/c_2013_778_en.pdf

3. Gupta RP-S, de Wit ML, McKeown D. The impact of poverty on the current and future health status of children. Paediatr Child Health. 2007;12(8):667-72.

4. Blumenshine P, Egerter S, Barclay CJ, Cubbin C, Braveman PA. Socioeconomic Disparities in Adverse Birth Outcomes. Am J Prev Med. 2010;39(3):263-72.

5. Gagnon AJ, Zimbeck M, Zeitlin J. Migration to western industrialised countries and perinatal health: A systematic review. Part Spec Issue Women Mothers HIV Care Resour Poor Settings. 2009;69(6):934-46.

6. Goldman N, Kimbro RT, Turra CM, Pebley AR. Socioeconomic Gradients in Health for White and Mexican-Origin Populations. Am J Public Health. 2006 Dec [cited 2015 Apr 1];96(12):2186-93.

7. Kimbro RT, Bzostek S, Goldman N, Rodriguez G. Race, Ethnicity, And The Education Gradient In Health. Health Aff (Millwood). 2008;27(2):361-72.

8. Racape J, Schoenborn C, Sow M, Alexander S, De Spiegelaere M. Are all immigrant mothers really at risk of low birth weight and perinatal mortality? The crucial role of socio-economic status. BMC Pregnancy Childbirth. 2016 Apr 8;16:75.

9. Sow M, Racape J, Schoenborn C, De Spiegelaere M. Is the socioeconomic status of immigrant mothers in Brussels relevant to predict their risk of adverse pregnancy outcomes? BMC Pregnancy Childbirth. 2018 Dec;18(1).

10. Urquia ML, Glazier RH, Blondel B, Zeitlin J, Gissler M, Macfarlane A, et al. International migration and adverse birth outcomes: role of ethnicity, region of origin and destination. J Epidemiol Community Health. 2009;64(3):243-51.

11. Racape J, De Spiegelaere M, Dramaix M, Haelterman E, Alexander S. Effect of adopting host-country nationality on perinatal mortality rates and causes among immigrants in Brussels. Eur J Obstet Gynecol Reprod Biol [Internet]. 2013;168(2):145-50.

12. Sow $M$, Feyaerts $G$, De Spiegelaere $M$. Profil des nouveau-nés bruxellois et impact sur la santé périnatale. In: Pauvreté en Belgique: Annuaire 2017. Lahaye, Willy ; Pannecoucke, Isabelle ; Vranken, Jan ; Van Rossem, R.; 2017. p. 147-67.

13. Auger N, Luo Z-C, Platt RW, Daniel M. Do mother's education and foreign born status interact to influence birth outcomes? Clarifying the epidemiological paradox and the 
healthy migrant effect. J Epidemiol Community Health. 2008 May 1 [cited 2014 Feb 9];62(5):402-9.

14. Auger N, Giraud J, Daniel M. The joint influence of area income, income inequality, and immigrant density on adverse birth outcomes: a population-based study. BMC Public Health. 2009;9(1):237.

15. Kramer MS, Platt RW, Wen SW, Joseph KS, Allen A, Abrahamowicz M, et al. A New and Improved Population-Based Canadian Reference for Birth Weight for Gestational Age. PEDIATRICS. 2001;108(2):e35-e35.

16. Statistics Canada. Dissemination area (DA). http://www12.statcan.gc.ca/censusrecensement/2011/ref/dict/geo021-eng.cfm

17. Moore S, Daniel M, Auger N. Socioeconomic disparities in low birth weight outcomes according to maternal birthplace in Québec, Canada. Ethn Health. 2009 Feb;14(1):6174.

18. Beaudoin $P$, Québec (Province), Ministère de l'immigration et des communautés culturelles. Portrait des femmes immigrées des minorités visibles recensées au Québec en 2006 et de leur participation au marché du travail. Montréal: Ministère de l'immigration et des communautés culturelles; 2012. http://collections.banq.qc.ca/ark:/52327/2162994

19. Alhusen JL, Bower KM, Epstein E, Sharps P. Racial Discrimination and Adverse Birth Outcomes: An Integrative Review. J Midwifery Womens Health. 2016;61(6):707-20.

20. Carlisle SK, Stone AL. Effects of Perceived Discrimination and Length of Residency on the Health of Foreign-Born Populations. J Racial Ethn Health Disparities. 2015;2(4):434-44.

21. Hatzenbuehler ML, Phelan JC, Link BG. Stigma as a Fundamental Cause of Population Health Inequalities. Am J Public Health. 2013;103(5):813-21.

22. Viruell-Fuentes EA. Beyond acculturation: immigration, discrimination, and health research among Mexicans in the United States. Soc Sci Med 1982. 2007 Oct;65(7):152435.

23. Bostean G. Does Selective Migration Explain the Hispanic Paradox? A Comparative Analysis of Mexicans in the U.S. and Mexico. J Immigr Minor Health. 2013;15(3):624-35.

24. Buttenheim A, Goldman N, Pebley AR, Wong R, Chung C. Do Mexican immigrants "import" social gradients in health to the US? Soc Sci Med. 2010;71(7):1268-76.

25. George MP. The Mexican American Health Paradox: The Collective Influence of Sociocultural Factors on Hispanic Health Outcomes." [Internet]. 2013. Available from: https://www.inquiriesjournal.com/a?id=663

26. Page RL. Positive pregnancy outcomes in Mexican immigrants: what can we learn? J Obstet Gynecol Neonatal Nurs JOGNN NAACOG. 2004;33(6):783-90. 
27. Urquia ML, Vang ZM, Bolumar F. Birth Outcomes of Latin Americans in Two Countries with Contrasting Immigration Admission Policies: Canada and Spain. Caylà JA, editor. PLOS ONE. 2015;10(8):e0136308.

28. Collins JW, David RJ, Rankin KM, Desireddi JR. Transgenerational Effect of Neighborhood Poverty on Low Birth Weight Among African Americans in Cook County, Illinois. Am J Epidemiol. 2009;169(6):712-7.

29. Urquia ML, Berger H, Ray JG, for the Canadian Curves Consortium. Risk of adverse outcomes among infants of immigrant women according to birth-weight curves tailored to maternal world region of origin. Can Med Assoc J. 2015;187(1):E32-40. Available from: http://www.cmaj.ca/cgi/doi/10.1503/cmaj.140748 


\section{SUPPLEMENTAL FILE 1}

Associations between preterm birth and SES, according to maternal place of birth

\begin{tabular}{|c|c|c|c|c|c|c|c|c|c|c|}
\hline & \multicolumn{10}{|c|}{ CRUDE ORs (CI 95\%) } \\
\hline & \multicolumn{2}{|r|}{ Canada } & \multicolumn{2}{|r|}{ Europe \& USA } & \multicolumn{2}{|c|}{ Latin America } & \multicolumn{2}{|c|}{ Central/West Asia } & \multicolumn{2}{|c|}{ East/Southeast Asia } \\
\hline & $\%$ & OR $(95 \% \mathrm{Cl})$ & $\%$ & OR $(95 \% \mathrm{Cl})$ & $\%$ & OR $(95 \% \mathrm{Cl})$ & $\%$ & OR $(95 \% \mathrm{Cl})$ & $\%$ & OR $(95 \% \mathrm{Cl})$ \\
\hline \multicolumn{11}{|l|}{$\begin{array}{l}\text { Maternal } \\
\text { education }\end{array}$} \\
\hline Univerty & 4.63 & 1 & 4.43 & 1 & 4.92 & 1 & 4.14 & 1 & 5.07 & 1 \\
\hline College & 5.86 & $1.27(1.19-1.37)^{a}$ & 4.71 & $1.06(0.87-1.30)$ & 6.27 & $1.28(1.03-1.60) \mathrm{c}$ & 3.66 & $0.88(0.67-1.15)$ & 7.08 & $1.43(1.20-1.69)^{a}$ \\
\hline High school & 7.70 & $1.71(1.60-1.82)^{\text {a }}$ & 6.08 & $1.39(1.12-1.73)^{b}$ & 7.49 & $1.56(1.28-1.89)^{\text {a }}$ & 5.42 & $1.33(1.04-1.68) \mathrm{c}$ & 6.49 & $1.30(1.07-1.58)^{\mathrm{b}}$ \\
\hline \multicolumn{11}{|l|}{ Income Quintile } \\
\hline Top & 4.86 & 1 & 5.03 & 1 & 5.65 & 1 & 4.16 & 1 & 5.18 & 1 \\
\hline Fourth & 5.66 & $1.17(1.08-1.28)^{\text {a }}$ & 4.11 & 0.81 (0.64-1.01) & 6.27 & $1.11(0.83-1.50)$ & 3.99 & $0.95(0.69-1.32)$ & 5.94 & $1.15(0.88-1.51)$ \\
\hline Midlle & 5.88 & $1.22(1.12-1.33)^{a}$ & 4.87 & 0.96 (0.76-1.19) & 6.43 & $1.14(0.85-1.53)$ & 4.45 & $1.08(0.79-1.46)$ & 6.07 & $1.18(0.91-1.53)$ \\
\hline Second & 6.22 & $1.29(1.18-1.41)^{a}$ & 4.58 & $0.90(0.71-1.13)$ & 6.49 & $1.14(0.86-1.53)$ & 4.90 & $1.19(0.88-1.60)$ & 6.20 & $1.21(0.94-1.55)$ \\
\hline Bottom & 6.87 & $1.42(1.29-1.58)^{\text {a }}$ & 5.06 & $0.99(0.78-1.25)$ & 5.80 & $1.02(0.76-1.37)$ & 4.76 & $1.15(0.85-1.54)$ & 6.56 & $1.28(1.01-1.62)^{c}$ \\
\hline
\end{tabular}

\begin{tabular}{|c|c|c|c|c|c|}
\hline & \multicolumn{5}{|c|}{ AJUSTED ORs (Cl 95\%) } \\
\hline & Canada & Europe \& USA & Latin America & Central/West Asia & East/South-E Asia \\
\hline \multicolumn{6}{|l|}{$\begin{array}{l}\text { Maternal } \\
\text { education }\end{array}$} \\
\hline Univerty & 1 & 1 & 1 & 1 & 1 \\
\hline College & $1.26(1.17-1.36)^{\text {a }}$ & $1.13(0.92-1.41)$ & $1.31(1.10-1.75)^{b}$ & $0.91(0.72-1.23)$ & $1.35(1.10-1.61)^{c}$ \\
\hline High school & $1.66(1.54-1.80)^{\text {a }}$ & $1.51(1.19-1.91)^{\mathrm{b}}$ & $1.67(1.33-2.09)^{\mathrm{a}}$ & $1.45(1.11-1.88)^{c}$ & $1.23(0.99-1.52)$ \\
\hline \multicolumn{6}{|l|}{ Income Quintile } \\
\hline Top & 1 & 1 & 1 & 1 & 1 \\
\hline Fourth & $1.02(0.84-1.16)$ & $0.80(0.63-1.01)$ & $1.02(0.71-1.38)$ & $0.94(0.71-1.34)$ & $1.13(0.85-1.54)$ \\
\hline Midlle & $1.03(0.86-1.18)$ & $0.93(0.73-1.17)$ & $1.07(0.75-1.41)$ & $1.10(0.80-1.52)$ & $1.11(0.83-1.46)$ \\
\hline Second & $1.09(1.10-1.23)^{c}$ & 0.85 (0.67-1.09) & $1.07(0.75-1.40)$ & $1.23(0.94-1.62)$ & $1.14(0.85-1.49)$ \\
\hline Bottom & $1.12(1.02-1.25) \mathrm{c}$ & $0.92(0.71-1.18)$ & $0.88(0.65-1.21)$ & $1.20(0.91-1.59)$ & $1.18(0.93-1.50)$ \\
\hline
\end{tabular}




\section{SUPPLEMENTAL FILE 2}

Associations between SGA and SES, according to maternal place of birth

\begin{tabular}{|c|c|c|c|c|c|c|c|c|c|c|}
\hline & \multicolumn{10}{|c|}{ CRUDE ORs (Cl 95\%) } \\
\hline & \multicolumn{2}{|r|}{ Canada } & \multicolumn{2}{|r|}{ Europe \& USA } & \multicolumn{2}{|r|}{ Latin America } & \multicolumn{2}{|c|}{ Central/West Asia } & \multicolumn{2}{|c|}{ East/Southeast Asia } \\
\hline & $\%$ & OR $(95 \% \mathrm{Cl})$ & $\%$ & OR $(95 \% \mathrm{Cl})$ & $\%$ & OR $(95 \% \mathrm{Cl})$ & $\%$ & OR $(95 \% \mathrm{Cl})$ & $\%$ & OR $(95 \% \mathrm{Cl})$ \\
\hline Maternal education & & & & & & & & & & \\
\hline Univerty & 7.59 & 1 & 7.75 & 1 & 9.79 & 1 & 8.79 & 1 & 10.16 & 1 \\
\hline College & 8.51 & $1.13(1.06-1.19)^{a}$ & 8.40 & $1.09(0.94-1.27)$ & 7.28 & $0.73(0.60-0.88)^{b}$ & 8.46 & $0.96(0.80-1.16)$ & 11.86 & $1.16(1.01-1.32)^{c}$ \\
\hline High school & 11.16 & $1.52(1.44-1.61)^{\mathrm{a}}$ & 9.64 & $1.27(1.06-1.51)^{b}$ & 8.46 & $0.85(0.72-1.01)$ & 9.33 & $1.07(0.89-1.29)$ & 11.67 & $1.16(1.00-1.34)$ \\
\hline Income Quintile & & & & & & & & & & \\
\hline Top & 7.50 & 1 & 7.52 & 1 & 8.26 & 1 & 8.28 & 1 & 9.45 & 1 \\
\hline Fourth & 8.43 & $1.13(1.06-1.22)^{a}$ & 7.86 & $1.04(0.88-1.24)$ & 8.98 & $1.06(0.82-1.39)$ & 8.85 & $1.06(0.84-1.35)$ & 12.06 & $1.32(1.07-1.62) \mathrm{c}$ \\
\hline Midlle & 8.77 & $1.19(1.10-1.27)^{\mathrm{a}}$ & 8.64 & $1.16(0.97-1.38)$ & 9.05 & $1.12(0.86-1.44)$ & 8.55 & $1.03(0.81-1.31$ & 11.08 & $1.17(0.95-1.44)$ \\
\hline Second & 9.67 & $1.32(1.22-1.41)^{a}$ & 8.01 & $1.07(0.89-1.28)$ & 8.22 & $0.99(0.76-1.28)$ & 8.41 & $1.01(0.79-1.29)$ & 11.19 & $1.21(0.98-1.47)$ \\
\hline Bottom & 9.97 & $1.36(1.26-1.47)^{a}$ & 8.75 & $1.18(0.98-1.42)$ & 8.96 & $1.09(0.84-1.41)$ & 10.15 & $1.25(0.99-1.57)$ & 10.85 & $1.12(0.93-1.36)$ \\
\hline
\end{tabular}

\begin{tabular}{|c|c|c|c|c|c|}
\hline & \multicolumn{5}{|c|}{ AJUSTED ORs (Cl 95\%) } \\
\hline & Canada & Europe \& USA & Latin America & Central/West Asia & East/South-E Asia \\
\hline \multicolumn{6}{|l|}{ Maternal education } \\
\hline Univerty & 1 & 1 & 1 & 1 & 1 \\
\hline College & $1.14(1.06-1.21)^{\mathrm{a}}$ & $1.15(1.02-1.38)$ & $0.80(0.67-1.05)$ & $0.95(0.79-1.18)$ & $1.24(1.07-1.43)^{c}$ \\
\hline High school & $1.56(1.46-1.66)^{\text {a }}$ & $1.35(1.11-1.63)$ & $0.98(0.81-1.19)$ & $1.07(0.87-1.31)$ & $1.25(1.06-1.46)^{b}$ \\
\hline \multicolumn{6}{|l|}{ Income Quintile } \\
\hline Top & 1 & 1 & 1 & 1 & 1 \\
\hline Fourth & $1.03(0.91-1.13)$ & $1.03(0.88-1.23)$ & $1.05(0.83-1.39)$ & $1.08(0.82-1.37)$ & $1.18(0.94-1.58)$ \\
\hline Midlle & $1.05(0.92-1.14)$ & $1.04(0.84-1.25)$ & $1.13(0.87-1.46)$ & $1.03(0.79-1.32)$ & $1.13(0.80-1.39)$ \\
\hline Second & $1.07(0.97-1.16)$ & $1.02(0.76-1.19)$ & $0.99(0.76-1.29)$ & $1.01(0.80-1.29)$ & $1.15(0.82-1.40)$ \\
\hline Bottom & $1.09(0.99-1.19)$ & $1.05(0.86-1.27)$ & $1.10(0.84-1.45)$ & $1.17(0.91-1.49)$ & $1.08(0.88-1.33)$ \\
\hline
\end{tabular}

